\title{
Way-finding strategies of blind persons in urban scale
}

\author{
Didem Kan-Kilic (iD, ${ }^{1}$ and Fehmi Dogan ${ }^{2}$ \\ ${ }^{1}$ Faculty of Fine Arts and Design, Department of Interior Architecture and Environmental Design, Izmir \\ University of Economics, İzmir, Turkey, ${ }^{2}$ Faculty of Architecture, Department of Architecture, İzmir \\ Institute of Technology, İzmir, Turkey
}

\begin{abstract}
The aim of this study was to determine whether urban environments with different prominent sensory inputs have an impact on the way-finding strategies of blind people and to identify these impacts, where applicable. We specifically investigated how blind people use their senses to compensate for the lack of visual information and how the priority of senses changes according to the urban context. The participants of the study consisted of nine congenitally blind individuals and the study took place in two urban settings: a dense urban district, Kemeralti district in Izmir; and an urban park, the Izmir Fair Park. During the learning phase, a first trial along the selected routes was conducted for each participant individually along with one of the researchers. In the test phase, the participants were requested to re-walk the route and verbally report the environmental cues they attended to. The participants' verbal reports were recorded and transcripts of the recordings were coded according to the environmental sensory inputs. In addition, the short-term memory of each participant was also evaluated. The results show that the characteristics of the urban environment seem to have an impact on way-finding strategies of blind individuals. It was found that the sound of the city and the echo from the environment are the most important factors for blind participants in the dense urban environment. Environmental boundaries provided echoes and gave a sense of enclosure that helped them orient themselves, whereas, in the park environment, the sense of enclosure was not enhanced due to a lack of boundaries in the environment.
\end{abstract}

Keywords: blind persons; sense of enclosure; senses; way-finding

Correspondence: Dr. Didem Kan-Kilic, Faculty of Fine Arts and Design, Department of Interior Architecture and Environmental Design, İzmir University of Economics, Sakarya Street No. 156, Balçova 35330, izmir, Turkey. Email: didem.kan@ieu.edu.tr

Received 19 January 2017. Accepted 3 August 2017.

As sighted people, we have very little knowledge about how blind people perceive large-scale urban environments and how they acquire spatial information of such complex urban environments. Studies in the literature have mainly concentrated on small-scale spaces (Dodds, Howarth, \& Carter, 1982; Gaunet \& Briffault, 2005; Herman, Herman, \& Chatman, 1983; Leonard \& Newman, 1967; Passini \& Proulx, 1988; Saerberg, 2010). In this study, we focused on how blind people collect spatial information during way-finding processes in urban settings. The aim of this study was to determine whether urban environments with different prominent sensory inputs and physical features have an impact on way-finding strategies of blind participants and to identify these impacts, where applicable.
We specifically investigated how blind people use their senses in two different urban environments and how the priority of senses changes according to the urban context. The research question of this study was as follows: While in a familiar urban context, which specific aspects of the environment do blind people focus on and use as cues in their way-finding process?

Gaunet and Briffault (2005) propose that blind individuals' ease of way-finding in urban environments relates to the complexity of the urban environment. They describe simple environments as "structured urban environments, i.e., streets bordered by narrow sidewalks, walls or fences, with cross- and T-intersections, crosswalks perpendicular to sidewalks, one-step crossing, and a less than 15-m-wide 
road." They define complex environments as "unstructured areas such as open areas, campuses or major roundabouts, which are usually avoided by blind pedestrians" (p. 397). Gaunet and Briffault (2005) found that the more complex and unstructured an environment is, the more difficult wayfinding is for blind people.

Passini and Proulx (1988) state that "to move freely in the large scale architectural and urban environment can be a difficult task for any person; but it can be an exasperating one for the visually impaired" (p. 228). Blind people require extensive storage of information regarding their environment because they cannot use visual sensory inputs to understand the spatial organization of their environment. In addition, as Steyvers and Kooijman (2009) argue, blind individuals have to rely on environmental information other than vision, such as vestibular, haptic, and auditory information. In order to reach the target, they should understand the spatial relations. Therefore, blind individuals are able to construct a cognitive map from non-visual cues of their surroundings (Steyvers \& Kooijman, 2009). Millar (1994) made significant contributions in the way other senses are used by blind people in perceiving the environment and in highlighting the multimodality of our spatial understanding. Millar claims that each of these senses, which are complementary to and which might overlap each other, is significant to understanding the environment.

In an unfamiliar environment, a blind person has many difficulties collecting spatial information and locating landmarks that make their way-finding process easier (Coughlan \& Manduchi, 2009). As Steyvers and Kooijman (2009) suggest, blind individuals' experiences in the environment are based on route-based information, which means that all collected environmental cues come from the route itself during the way-finding process. They orient themselves according to the bounding walls of a given space, which they primarily locate through echolocation (Schenkman \& Nilsson, 2010). Gaunet (2006) showed that blind individuals' difficulties in accessing information in unfamiliar environments consist of not knowing the following:

[W]hich way to walk to the destination, keeping track of the direction to the destination, knowing which way is faced, which street corner the pedestrian is on, when and where to turn, finding a new store or office destination, learning about new bus stop locations, and learning about new locations the pedestrian is passing. (p. 341)

Giudice, Bakdash, and Legge (2007) claim that verbal descriptions have an important role during this process and they suggest that it is possible to construct cognitive maps from verbal descriptions and to solve way-finding problems. Along similar lines, verbal descriptions were used in this study to introduce a specific route to blind individuals while they were walking along the route to help them learn (i.e., encode) the urban environment.

Senses of blind individuals are very important during way-finding; however, personal memory also has a very significant role, especially in familiar environments. For example, Thinus-Blanc and Gaunet (1997) suggest that in order to reach a target, distance and direction information are related to the information in the memory of individuals. In the absence of vision, other sensory modalities, such as audition, touch, and olfaction, in the environment are heightened during the way-finding processes of blind individuals. However, do all of these modalities have the same significance during the way-finding processes of blind individuals? We explored this question in comparing blind individuals' way-finding strategies in two different urban contexts.

In this study, we hypothesized that navigation strategies of participants would differ in the two urban settings selected as study environments. Kemeralti is a complex, crowded urban environment that includes many obstacles, such as barriers, shop counters, unorganized buildings, and various types of sensory information that may or may not make way-finding more difficult for blind individuals. One might presume that in a complex built environment, wayfinding is more difficult than way-finding in a simple urban environment; however, following Steyvers and Kooijman (2009), it is possible that way-finding in complex environments might be easier. This could primarily relate to a heightened sense of enclosure in such environments because of roads being aligned with buildings and walls that help echolocation. We supposed that in a complex urban environment that included many obstacles, auditory information would be the most used sense when blind people operationalized their way-finding strategies as we presumed that these obstacles would create an echo for blind individuals that would help them in their way-finding strategies. In comparison, we predicted that in an urban environment that did not heighten the sense of enclosure, such as an urban park, way-finding might be more difficult and 
Table 1

Information About the Participants in the Case Study in lizmir, Turkey.

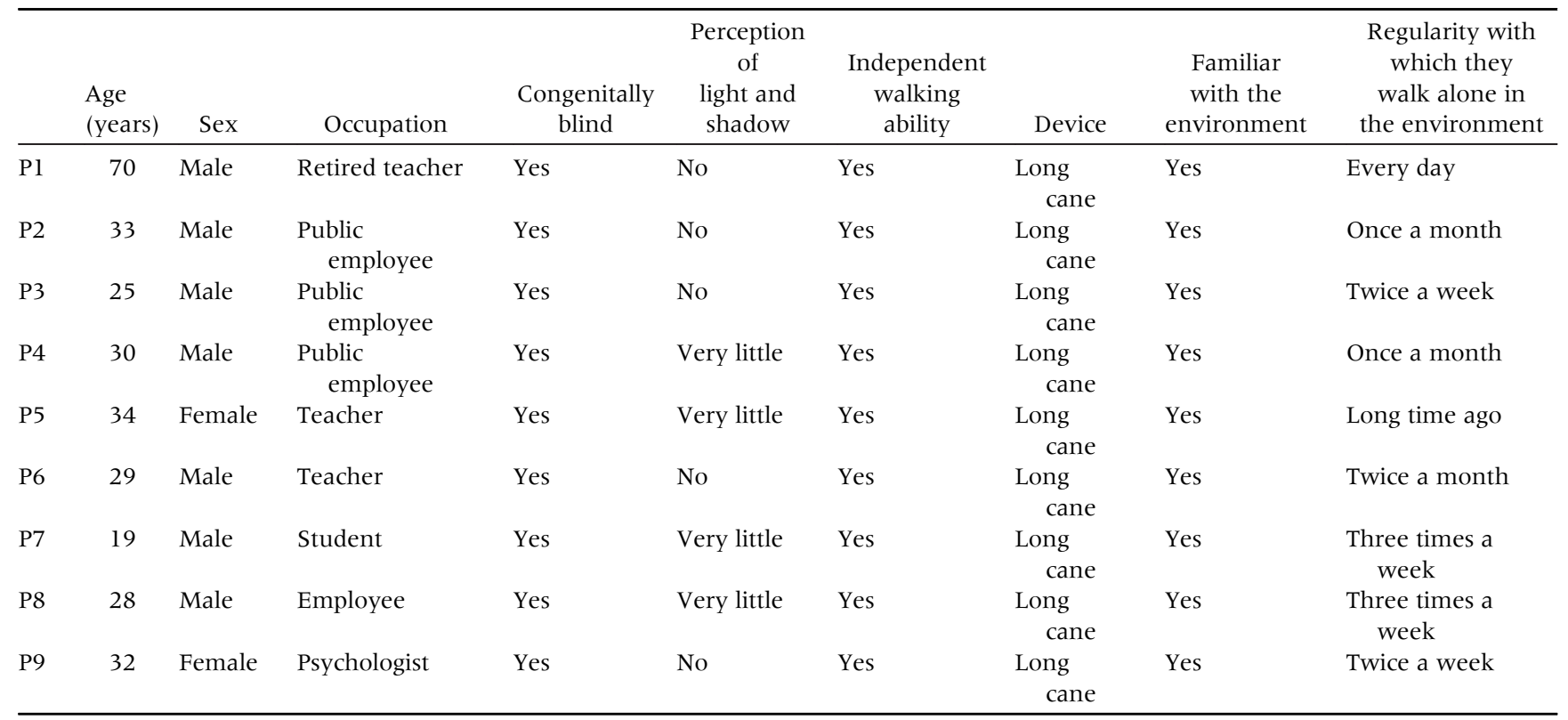

tactile information would be the most used sense due to minimal echo from the environment.

\section{Method}

Two different urban environments in İmir, Turkey, were chosen as the study settings. The first was in a complex urban fabric, namely the Kemeralti District in İzmir, and the other was an urban park, the İzmir Fair Park. Kemeralti has a complex urban fabric with streets of different lengths, orientation, and lacks a clearly intelligible street pattern. It is separate from the rest of the city with clear borders and is linked to the rest of the city with specific entry points. Altogether, these urban characteristics of the area make way-finding a complex task, not only for blind people but also for sighted people.

The second selected route was in the most important recreation area of the city, the İzmir Fair Park, with many trees and a clear pedestrian circulation system. The park includes only a few buildings, such as the Parachute Tower, Open Air Theatre, and culture and art centers. The buildings are located within a large green urban void.

\section{Participants}

In the study, there were nine congenitally blind participants (seven men, two women). The mean age of the participants was 33 years. The participants were selected based on their type of blindness, employment status, ability of independent mobility, and familiarity with the study settings (Table 1). Only those individuals who were congenitally blind, employed or studying at university, with independent mobility, and who were familiar with the study environment were accepted as participants. Half of them had no perception of light and shadow; the rest had a negligible perception of light. All participants could walk alone in the city and used long canes during their way-finding process. All participants were familiar with the study environment and walked alone in Kemeralti and the Izmir Fair Park at least once a month; however, they were unfamiliar with the proposed specific routes.

\section{Study area and routes}

The initial visit to the area was made by one of the researchers alone to identify the turning points with strong reference points with regards to the sensory information that they provide. The routes determined in these two urban environments were similar to each other in regards to length and number of turning points, but differed from each other significantly in terms of the sensory cues they provided given the differences in the physical environment. The selected route length in Kemeralti was $700 \mathrm{~m}$ (Figure 1) and in the Fair Park was $710 \mathrm{~m}$ (Figure 2). 


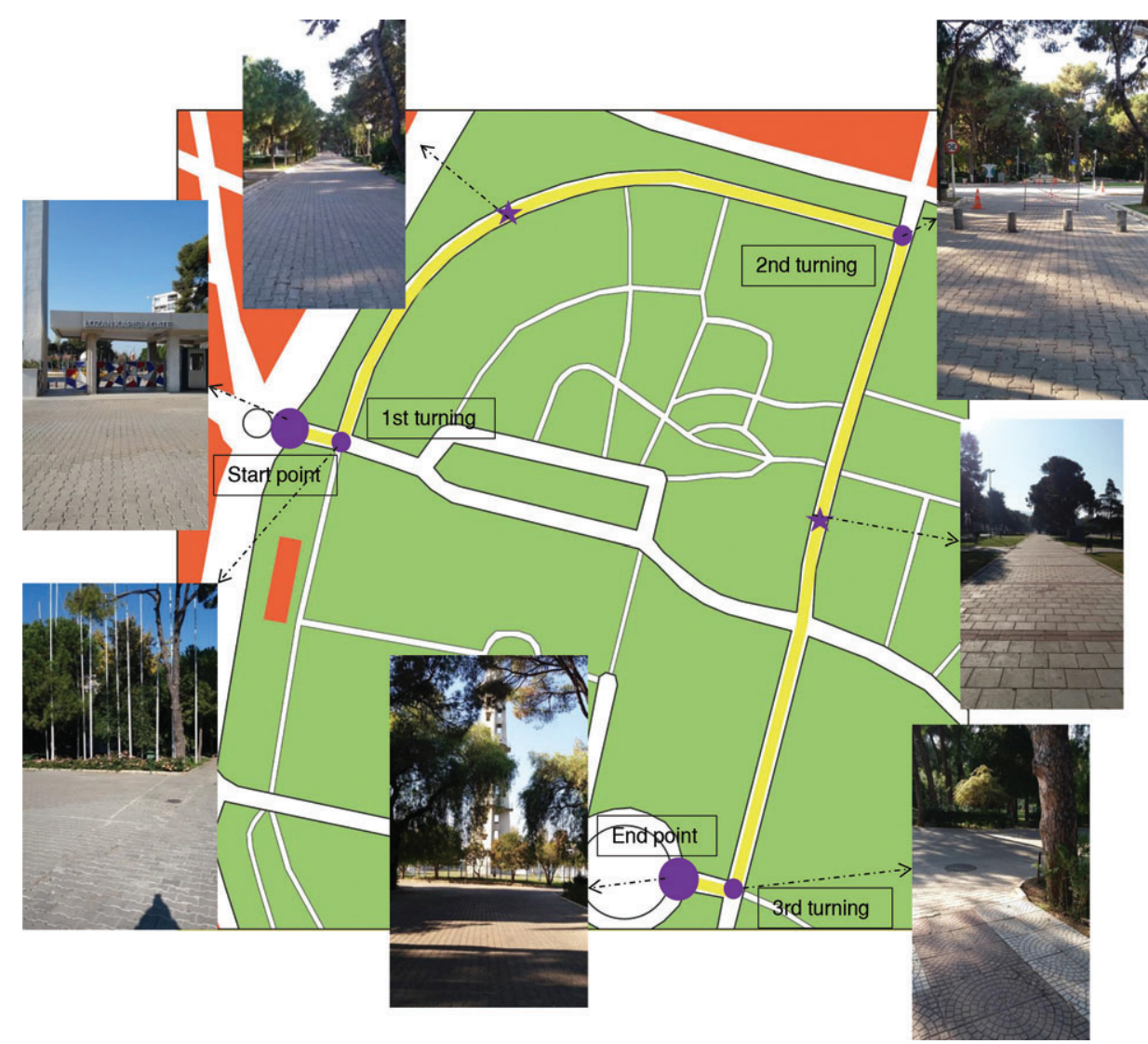

Figure 1. The selected route in izmir Fair Park. [Color figure can be viewed at wileyonlinelibrary.com]
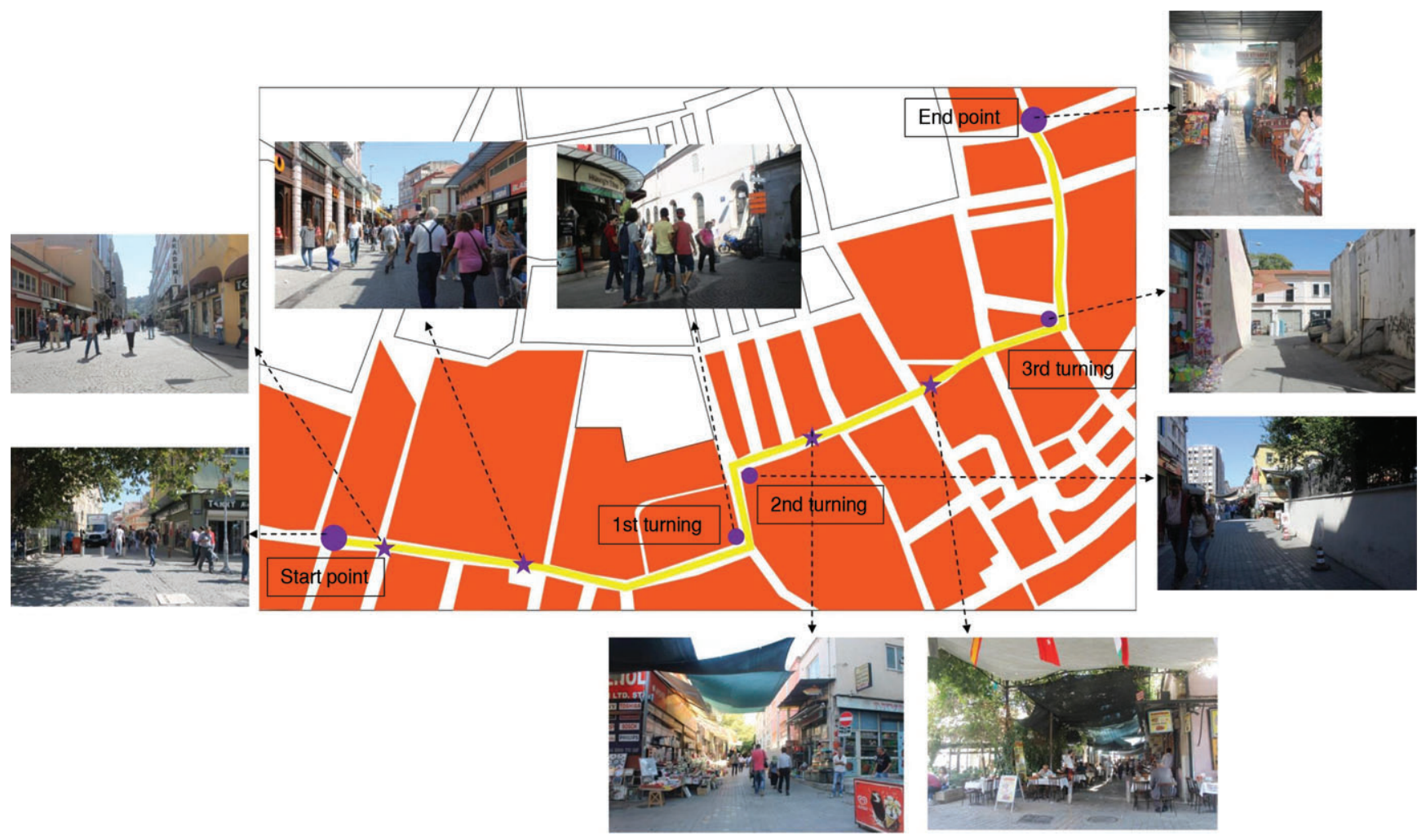

Figure 2. The selected route in Kemeralti. 
With an average walking speed, a blind individual would reach the target in about $16 \mathrm{~min}$. Three turning points that have different sensory cues for the participants were defined in each route. The time travelled in each route was around $7 \mathrm{~min}$ for a sighted subject. However, the speed would change according to the participants' speed of walking.

The important criterion to determine the route was to include turning points with strong reference points for the blind participants. The selection criterion of the route in the park was primarily related to the locations of the buildings in the park. The park did not provide as much sensory information as Kemeralti, which we thought would have an impact on participants' way-finding strategies. Kemeralti has a clearly different urban identity with an intelligible street pattern. Furthermore, Kemeralti heightens the sense of enclosure with narrow streets bordered by adjacent buildings, while the park gives a feeling of openness. We expected that the distinction between an open versus enclosed urban space would have an impact on way-finding strategies of blind individuals.

\section{Procedure}

All the participants were informed about the study's scope. The research was conducted first in Kemeralti and second in the park on a pre-scheduled day. After the study was conducted in Kemeralti, each participant was given a break of an hour to rest before the second test in the park. Participants were tested individually at the same time of a different weekday between 1:00 p.m. and 4:00 p.m. and in similar weather conditions to compare the environmental cues that they used in two different urban environments. The trials took around $2 \mathrm{hr}$, including the initial interview, in both urban environments. Weekdays were chosen to conduct the study, especially in Kemeralti, because this place has a different identity and crowding level during the weekends. We did not counterbalance the order of the study settings, which might have had some effect on the results. We think that the impact would be minimal as participants were familiar with both environments and the way-finding tasks were no different from what they would do in their daily life, requiring no intense physical or cognitive effort on their part.

The participants signed a consent form that was prepared by the researchers. The form included information about the researchers, the content of the study, and where the collected information would be used after the study. An initial interview including 36 questions was conducted before each trial to measure likely participants' independent mobility abilities and their familiarity with the study environments. Based on their responses, interviewees who had a sustained independent mobility within urban environments and who were familiar enough with the study environment were selected as participants of the study. A video recorder was used to record the participants' experiences and their verbal reports during the walking tour. The videos were later used to analyze the verbal reports of the participants.

In this study, multi-trial learning tasks, consisting of a learning phase, test phase, and post-test, were used to help blind participants in accomplishing the way-finding task better as suggested by Corazzini, Tinti, Schmidt, Mirandola, and Cornoldi (2010). A learning phase in the procedure allowed the participants to become more familiar with the selected route. The participants were familiar with the study environments as it was determined in the participant selection process; however, they were not familiar with the proposed route.

\section{Preparation phase}

In the preparation phase, each participant's consent was taken prior to the study. The researcher gave the participants initial instructions about each urban environment before the walking tour and the duration of the research. In addition, an initial interview was conducted with each participant to assess their independent way-finding abilities and understand their familiarity with the study environment. After an interview with every likely participant, those who were found to have self-mobility and who were familiar with the study settings were accepted as a participant of the study.

\section{Learning phase}

The learning phase was the trial phase to introduce the routes to the participants, who were expected to learn the length of the route, the main features along the route, the end-point, and the turning points. This phase included only one trial along the selected routes and was conducted for each participant together with one of the researchers, who verbally described the specific route and the turning points by way of identifying the main spatial features without giving any detailed information with regards to any environmental sensory input. The researcher gave the same 
Table 2

Coding System.

Environmental

cues Examples from the transcripts

Auditory • "Woman wearing high-heeled shoes is passing by me. The sound of heels helps me understand the place of the wall around me. And also I feel the person carrying the bag in his left hand. The sound of heels and the sound of the bag help us orient ourselves in such a crowded environment."

- "There is a high wall in front of me. My words hit the wall and come back."

- "There is a big gap on my right side. When I turn right, my voice travels out in the air. It doesn't hit any obstacles."

Tactile

- "I constructed a cognitive map of this space in my mind. For example, the rough floor texture with restaurants' patios on both sides is one of the references for me. When I passed these patios, the floor texture changed from rough to smooth."

- "Now, the sun hits on the back of my neck. It is following me. I can recognize the row of trees while the sun appears and disappears. Therefore, I can follow the shadow of the trees along the route."

Olfactory

- "When I need extra information for wayfinding in such a crowded environment, I follow the olfactory sensory inputs, such as coffee, corn, and new clothes."

- "We construct cognitive maps in our minds differently than you do. For example, you generate it based on visual information; however, we construct it based on information such as the voice of coffee machine or the smell of coffee."

information with the same words to each participant and told the participants to learn the environmental cues that would help them in the test phase. The same procedure was followed in both study environments. This learning phase also checked participants' ability to walk alone without holding their arms and each participant used a long cane during this phase. The participants were told that when the walking tour began, they should get to the destination as fast as possible following the pre-determined route.

\section{Test phase}

In the test phase, the participants were requested to re-walk the route and to talk about their experiences. In addition, they were asked to talk about environmental cues that helped them during their way-finding. In this phase, the researcher did not provide any help to reach the target. In addition, the researcher did not talk with the participant during the way-finding process. However, if participants felt lost or were confused, they could request help from the researcher. The participants' verbal reports were recorded during the way-finding process with the video recorder.

\section{Post-test phase}

In the post-test phase, the participants were requested to evaluate the walking tour. They talked about environmental cues that they focused on during way-finding and were asked about whether they got lost and, if so, where and why. In addition, they were asked to identify and describe the most difficult part of their experience. These accounts included similar information with the concurrent verbalizations; therefore, they were not included in the analysis. The results of the post-test phase were used to better understand the blind individuals' way-finding processes.

\section{Measures}

Verbal descriptions of the participants that were recorded during the way-finding process in two different urban environments were first transcribed verbatim. The transcripts of the recordings were then coded by the researchers according to the source of information that participants used during way-finding: either environmental input (i.e., the information gathered while performing the task) or memory retrieval (which corresponds to their previous knowledge). The environmental sensory information was divided into three categories: (1) auditory information (sound); (2) tactile information (consisting of three sub-categories: texture, air movement, and temperature); and (3) olfactory information (smell). The short-term memory of participants that corresponded to their previous knowledge was also evaluated as a fourth category. This information was gained during the learning phase and participants recalled this information during the way-finding process (Table 2). An independent coder who was not directly involved in the study coded $15 \%$ of verbal reports. The coder was given the coding system, which was described in detail. The agreement with the independent coder was $83 \%$, which we considered sufficient for further analysis.

Other measures evaluated included the following: Time spent to reach the target (which indicated the duration between the starting point and the finishing point) and error (the total number of wrong turns [turns other than the predefined ones] that the participants took). In addition, task 
Table 3

Distribution of Sensory Inputs and Information from Memory in the Kemeralti District.

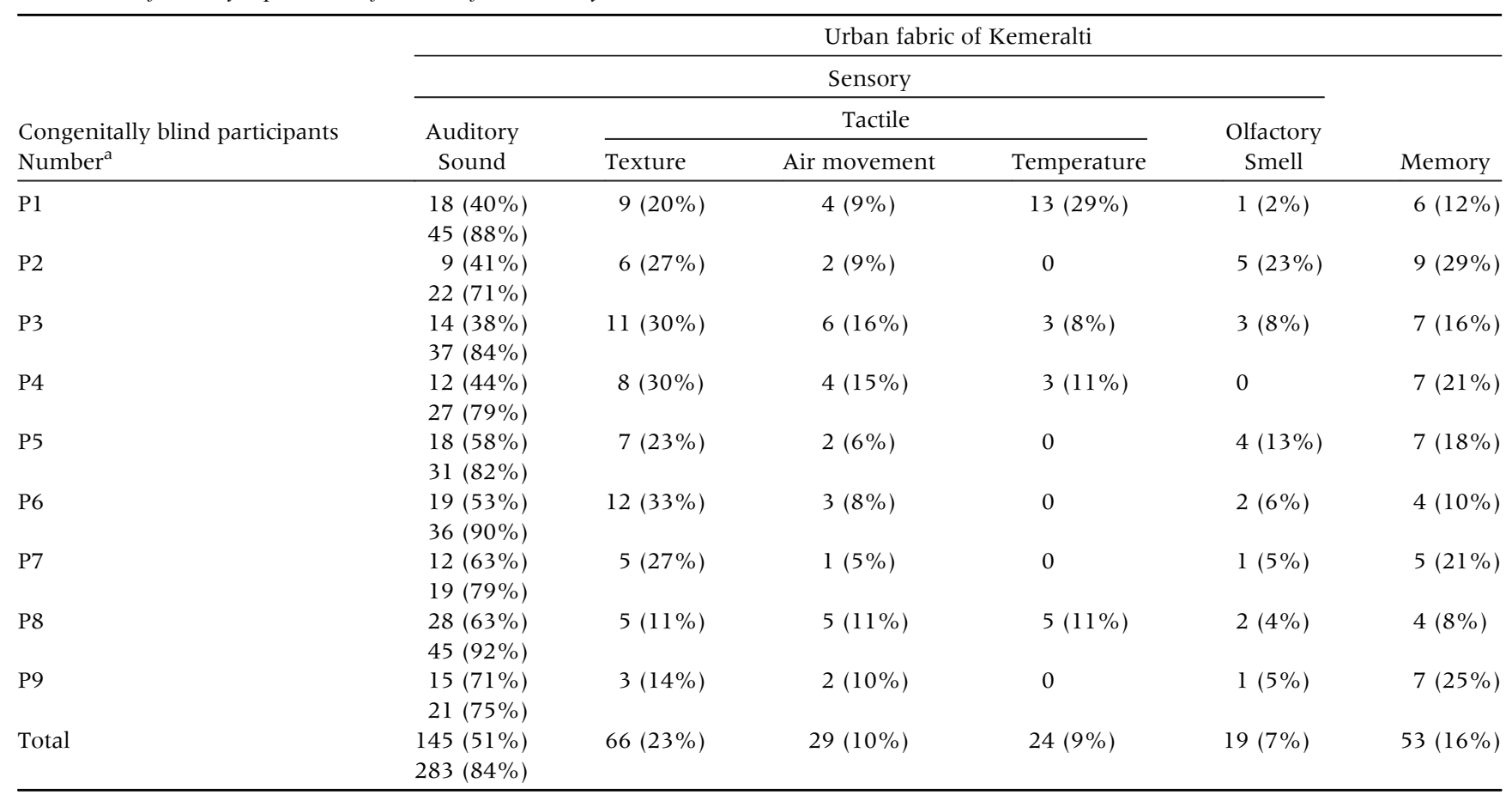

${ }^{\mathrm{a}}$ Individual participants are indicated as $\mathrm{P} 1, \mathrm{P} 2$, etc.

accomplishment performance was operationalized by task success, which corresponds to reaching the final destination. If participants were not able to reach the final destination, they were considered to be "lost."

\section{Results and discussion}

\section{Findings in Kemeralti}

The results from concurrent verbalizations of participants from the Kemeralti leg of the study are given in Table 3 . Table 4 presents the quantitative results from this leg of the study.

\section{Table 4}

Quantitative Findings Informing the Kemeralti Study.

\begin{tabular}{lccc}
\hline$N^{\mathrm{a}}$ & Reached the destination & Time $(\mathrm{min})$ & Number of errors \\
\hline P1 & $\checkmark$ & 21.30 & 4 \\
P2 & $\checkmark$ & 14.10 & 3 \\
P3 & $\checkmark$ & 15.36 & 1 \\
P4 & $\checkmark$ & 14.50 & 2 \\
P5 & $\checkmark$ & 16.35 & 0 \\
P6 & $\checkmark$ & 12.15 & 0 \\
P7 & $\checkmark$ & 14.25 & 0 \\
P8 & $\checkmark$ & 15.20 & 0 \\
P9 & $\checkmark$ & 11.53 & 0 \\
\hline
\end{tabular}

${ }^{\text {a }}$ Individual participants are indicated as $\mathrm{P} 1, \mathrm{P} 2$, etc.

\section{Finding 1}

All of the participants reached the target without getting lost. Sound (51\%) was the most used environmental sensory input during way-finding in Kemeralti. Auditory cues were vital for the way-finding processes of congenitally blind participants because they used auditory cues to estimate their distance from the obstacles and to understand where they were, as proposed by Portugali (1996). Portugali mentions that blind people's navigation in outdoor environments is performed by assessing the distance of a sound source, the estimation of the location of landmarks and reference points that help them to orient themselves. Some of the participants in this study mentioned that stationary sound sources, such as air-conditioners, and nonstationary sound sources, such as high heels, helped them orient themselves in Kemeralti. Participant (P) 1 explained this as follows:

P1: Woman wearing high-heeled shoes is passing by me. The sound of heels helps me understand the location of the wall around me. And also I feel the person carrying the bag in his left hand. The sound of heels and the sound of the bag help us orient ourselves in such a crowded environment. ${ }^{1}$ 
Some of the participants also thought that their wayfinding process relied primarily on echoes, which help them estimate the shape and size of obstacles nearby. This is also supported by Kellogg (1962) and Rice (1967). These researchers suggested that echoes help blind individuals determine the type of outdoor environment in which they are located and also to determine the size and the shape of obstacles that they come across during way-finding (Kellogg, 1962; Rice, 1967). A statement of one of the participants who relied most on echoes is as follows:

P8: There is a high wall in front of me. My words hit the wall and come back ... There is a big gap on my right side. When I turn right, my voice travels out in the air. It doesn't hit any obstacles.

As cited in Ashmead and Wall (1999), the echo of the city helps blind people walk parallel to a wall or to an obstacle because the wall creates a wall of sound. Freksa (1999) suggests that blind people gain this specific spatial knowledge by exploring the environment and memorizing landmarks. The continuity of solid-void organization leads them to plan how to walk as a strategy of learning and remembering a route. They orient themselves according to the walls of a given space. Therefore, solids can create continuous barriers and a feeling of enclosure and voids create break-points that can be references for blind individuals' way-finding processes. Some of the participants in this study referred to the importance of solid-void organization of an environment and how this organization helps them in their way-finding processes as follows:

P5: I cannot walk easily in wide, open areas because in wide, open areas it is difficult to find references to delineate my path. I cannot control myself in reference to the environment in such areas. However, in this route I can take the buildings as references to control myself during way-finding. My cane's sound hits the walls of the buildings and comes back at me.

\section{Finding 2}

As shown in Table 3, smell (7\%) was the least used and temperature the second least used environmental cue in Kemeralti. However, according to the findings for each participant, olfactory information was used by all participants except P4. On the other hand, temperature was used by P1 mostly and additionally by only three participants.
Therefore, it could be said that the participants could not rely on olfactory information or thermoperception. This is probably related to the non-stationary sources of smell and temperature. Olfactory information can easily change according to other environmental features, such as wind, as mentioned by one of the participants:

P4: To take olfactory cues as a reference can't be always correct. They can easily change according to the direction of the wind or the store can be closed at that particular time. Olfactory cues aren't reliable for me.

Ferdenzi, Coureaud, Camos, and Schaal (2010) state that there are many studies on auditory and tactile information in environments; however, there are not many studies on the sense of smell. For blind individuals, if there is no access to auditory or tactile environmental inputs, olfaction may be particularly important. For example, Kemeralti is an urban environment that has a high level of crowding. If the participants were not able to access other environmental cues, they might have needed olfactory cues to orient themselves. One of the participants mentioned this as follows:

P3: When I need extra information for way-finding in such a crowded environment, I follow the olfactory sensory inputs, such as coffee, corn, and new clothes.

\section{Finding 3}

Blind people generate cognitive maps in their minds differently than sighted people. Blind people store primarily non-visual information to construct their cognitive maps. Some of the verbalizations from our participants describe how blind individuals might use this non-visual information to generate cognitive maps as follows:

P5: We construct cognitive maps in our minds differently than you do. For example, you generate it based on visual information; however, we construct it based on information such as the voice of a coffee machine or the smell of coffee.

P7: I constructed a cognitive map of this space in my mind. For example, the rough floor texture with restaurants' patios on both sides is one of the references 
Table 5

Distribution of Sensory Inputs and Information from Memory at the lizmir Fair Park Study.

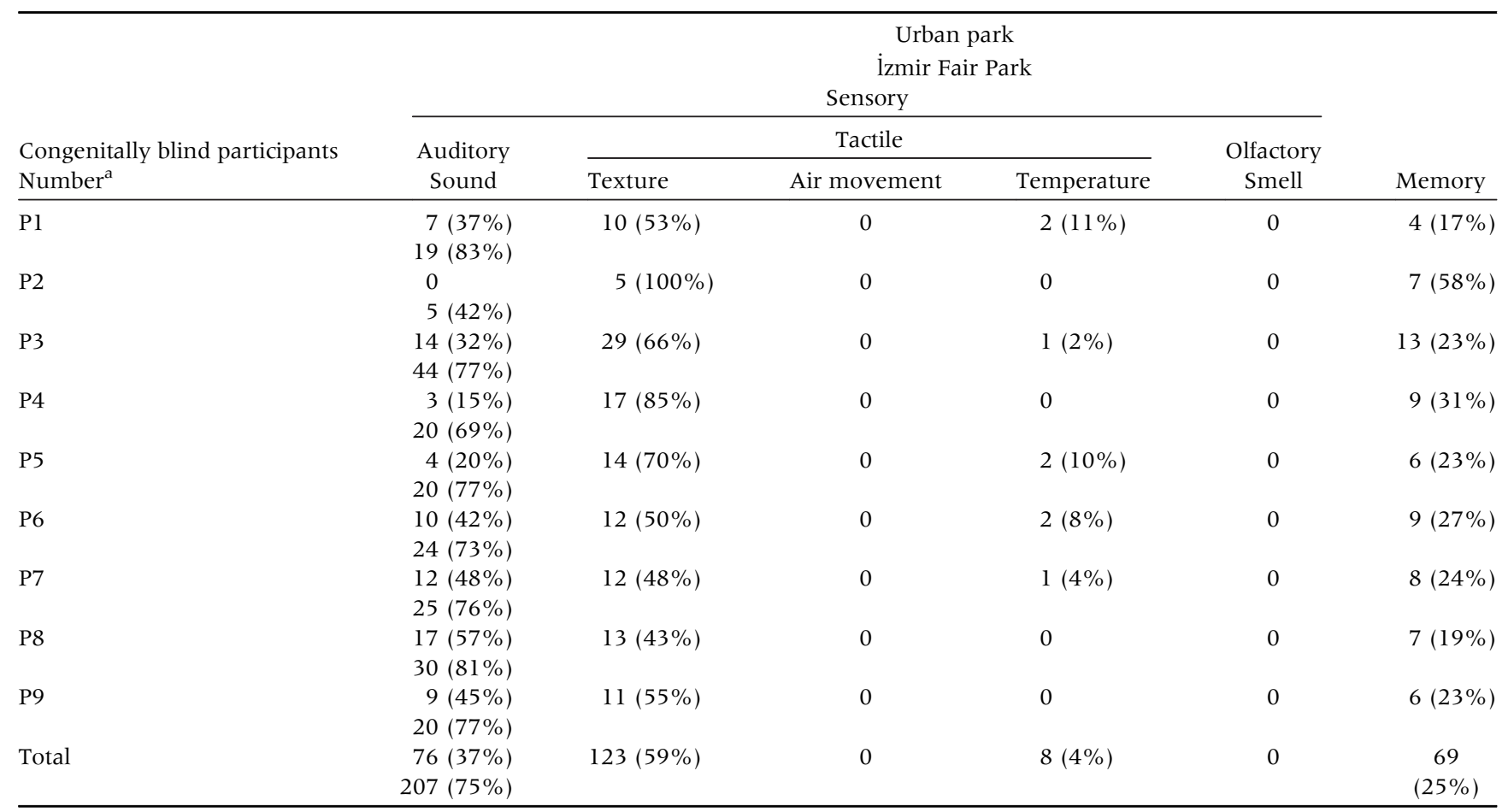

${ }^{\mathrm{a}}$ Individual participants are indicated as $\mathrm{P} 1, \mathrm{P} 2$, etc.

for me. When I passed these patios, the floor texture changed from rough to smooth. Another reference to construct a cognitive map is the smell of coffee. This place is always located at the same corner. Or at the third turning point, there was an air-conditioner sound. I coded this place in my mind as the third turning point. Therefore, our cognitive maps are based on sound, smell and texture.

Millar (1988) hypothesized that blind individuals reach a target by previously memorized movements and they code this information as part of their cognitive maps. In addition, Portugali (1996) argues that this type of information is

Table 6

Quantitative Findings Informing the lzmir Fair Park Study.

\begin{tabular}{lccc}
\hline$N^{\mathrm{a}}$ & Reached the destination & Time $(\mathrm{min})$ & Number of errors \\
\hline P1 & $\checkmark$ & 25.16 & 3 \\
P2 & $\checkmark$ & 18.53 & 5 \\
P3 & $\checkmark$ & 27.53 & 3 \\
P4 & $\checkmark$ & 16.15 & 2 \\
P5 & $\checkmark$ & 19.20 & 1 \\
P6 & $\checkmark$ & 16.19 & 1 \\
P7 & $\checkmark$ & 17.35 & 1 \\
P8 & $\checkmark$ & 29.38 & 1 \\
P9 & $\checkmark$ & 18.00 & 1 \\
\hline
\end{tabular}

${ }^{\mathrm{a}}$ Individual participants are indicated as $\mathrm{P} 1, \mathrm{P} 2$, etc. generally gained via exploratory search or repetitive travel behavior in a local environment, as it was done in this case study. One of our participants explained how she stored and used the information that was gained in the learning phase of the case study as follows:

P4: At the end of the wall, there is a second turning point. I cannot remember the names and the functions of places. I create a cognitive map in my mind and I have my own references to remember places. In order to remember the second turning point, I don't need to memorize the mosque on my right. The important thing is when the wall finishes on the right side, there is a turning point there.

The auditory, tactile, and olfactory cues from an environment give information to blind individuals about their surroundings. They collect references based on these nonvisual aspects of their surroundings and construct their cognitive maps in their minds accordingly.

\section{Findings from the Izmir Fair Park}

Table 5 shows the results from concurrent verbalizations of participants from the Izmir Fair Park leg of the study. 
Table 6 presents the quantitative results from this leg of the study.

\section{Finding 1}

All the participants reached the target without getting lost in the park, as in Kemeralti. However, since the park offers different types of sensory information compared to Kemeralti, the frequency of the chosen senses is different from the ones in Kemeralti. Tactile information (59\%) was the most used cue at the Fair Park. One possible reason for this could be related to the environment. At the park, there are not many sources of sound and the existing ones are far away from the selected route. Therefore, it is possible that participants used sense of touch more than sense of hearing during way-finding. One participant explained the reasons for use of tactile information in this urban space as follows:

P8: At this place, there are not many elements that can be taken as references. However, the floor takes and directs us where we want. There is no chance to go in another direction out of your way.

As proposed by Bloomer and Moore (1977), the sense of touch provides concrete information to participants in comparison to hearing, smelling, and even seeing, which they claim are more abstract in terms of bodily experience. They also add that spatial experiences might be gained from touching. The blind participants described the Izmir Fair Park as an open environment whereas they did not characterize Kemeralti in this way. They described the Izmir Fair Park as an open environment because there are not enough buildings, walls or barriers to create a feeling of enclosure for the participants. They indicated that they should follow something not to get lost in such an open environment and added:

Table 7

Comparison of Two Different Urban Contexts.

\begin{tabular}{lcc}
\hline & \multicolumn{2}{c}{$\begin{array}{c}\text { Congenitally blind } \\
\text { participants }\end{array}$} \\
\cline { 2 - 3 } & $\begin{array}{c}\text { Sensory } \\
\text { inputs }\end{array}$ & $\begin{array}{c}\text { Memory } \\
\text { retrieval }\end{array}$ \\
\hline $\begin{array}{l}\text { Urban district (Kemeralti } \\
\text { District) }\end{array}$ & $283(84 \%)$ & $53(16 \%)$ \\
Urban park (Izmir Fair Park) & $207(75 \%)$ & $69(25 \%)$ \\
\hline
\end{tabular}

P1: The ground is smooth at the Fair Park. However, I need to find an edge as a reference. Without following anything on the ground, I cannot go straight.

P4: At the Izmir Fair Park, the most important reference for us is the curbs. They are always stable there.

P9: The ground takes us where we want to go. The ground directs us.

Open spaces are particularly problematic for blind individuals (American Foundation for the Blind, 2015) because blind people may think that these spaces provide an unlimited freedom, while providing few reliable sensory inputs for navigation and orientation. Open spaces are difficult to navigate because there are no obstacles that create echo for blind individuals to make navigation easier. The Izmir Fair Park is an example of such an open and difficult environment to navigate and consequently tactile information seems to be the primary sensory information used by the participants.

Gaunet and Briffault (2005) state that, "sunshine appearing and disappearing, gusts of wind as one rounds a street corner can be felt by the skin and provide information about crossroads" (p. 271). One participant in the current study felt the sunshine better than the other participants and used this information along the walking tour:

P1: Now, the sun hits on the back of my neck. It is following me. I can recognize the row of trees while the sun appears and disappears. Therefore, I can follow the shadow of the trees along the route.

This participant also claimed that blind participants can see the space with their skin, as Pallasmaa (2005) proposed, and the participant added:

P1: Our face works as the eye. We can see with our faces, because our faces are always in the process of collecting information from the surroundings.

\section{Finding 2}

We found that air movement and smell were not used by participants at all during the way-finding process in the park. This is probably related to the physical features of the 
environment. This environment offers a homogeneous smell of a green environment and there were no other sources of smell. Koutsoklenis and Papadopoulos (2011) state that the role of olfaction during way-finding relates to the direction of the wind, the stability of the odors to which one is attuned, and other distracting smells in the environment. They state that "smells also come from natural elements (the ground, sea, and trees, for example), from animals (such as horses), and from other objects or attributes that produce distinctive smells (like a garbage can or a sewer)" (Koutsoklenis \& Papadopoulos, 2011, p. 699). On the contrary, the İzmir Fair Park cannot provide any of these sensory inputs to the participants in terms of smell and air movement. One of the participants added as follows:

P9: Olfactory cues are distributed homogeneously. In addition, there are no obstacles around to cut the air. Therefore, it is difficult to recognize them in such a wide area.

\section{Finding 3}

The obstacles along a path help blind individuals estimate their distance to an object, and to understand their location and direction, as also suggested by Millar (1988). The learning phase helped them memorize the reference points and understand the features of the environment. One of the participants stated the following:

P3: We came across the race track and there is a low wall on my right side. Now, I understand that I am on the correct path because of this fixed obstacle here. This is one of the references for me along this path. In addition, sometimes there will be crossroads on my way; however, I will go straight until I find the building on the right side which is another reference for me.

\section{Finding 4}

As shown in Table 7, the participants used more sensory information in Kemeralti than in the İmir Fair Park and more information retrieval from memory in the park than in Kemeralti.
The chosen routes in the two urban environments had the same length and the same number of turning points. Each turning point in the two urban contexts provided strong sensory information. Kemeralti provided richer and more diverse sensory cues for the participants than the lzmir Fair Park in the form of non-visual inputs, such as sound, touch, and smell. When sensory inputs were less pronounced, as in the İzmir Fair Park, participants relied more on memory retrieval. In order to create a cognitive map of an environment and reach the target in the park, it was important to memorize the obstacles and reference points. When the urban environment supported echolocation, as in Kemeralti, participants relied heavily on auditory information, which helped them feel a sense of enclosure and directionality, whereas when echolocation was less reliable because of a lack of echoes from enclosing walls along a path, the participants were more dependent on tactile information. This seems to support our initial hypothesis. The qualitative data together with quantitative data provide some support for the claim that the environmental setting is likely to impact way-finding strategies in terms of information used. We did not, however, run a statistical analysis to firmly confirm or refute the hypothesis.

\section{Conclusion}

In this study, there were two urban contexts that offered different environmental features. The results show that when the urban context was changed, the participants' wayfinding strategies changed according to the features of an environment. We conclude that the context in which blind people navigate could have a significant impact on their strategies of way-finding; that is, in Kemeralti, the participants were more dependent on environmental cues, whereas in the Izmir Fair Park they were more dependent on their internal representations of the environment. For example, sense of hearing was the most used sense by the participants in Kemeralti. In the park, there are few sources of sound as a reference for them. The participants, therefore, mostly used tactile information instead of auditory input. Sense of touch was the most used sense by the participants in the park. Sense of smell was less significant than sense of hearing and sense of touch in both urban environments.

Before the study was conducted, it was expected that participants would reach the target easier in the park than in Kemeralti due to a fewer number of obstacles. However, 
the participants reported that they felt lost in Izmir Fair Park because of the openness and lack of enclosure. The results show that the participants used less sensory information during their way-finding processes in the park. When the participants had obstacles and boundaries, which help them orient themselves in an environment, these create a feeling of enclosure for the participants. However, in the park, the sense of enclosure was almost lacking, which made navigation harder.

Another important finding was that the sound of the city and the echo of the environment were the most important factors for blind participants in a dense urban environment, as mentioned in the literature. When there were not enough solid structures along their path, which would create echoes for blind individuals, they substituted hearing with another sense, which, in the Izmir Fair Park case, was the haptic sense.

The study's sample size was limited, which prevented us from conducting further statistical analysis to firmly confirm or refute the initial hypothesis of the study. In future studies, it could be possible to recruit more participants to conduct further statistical analysis to firmly test our hypothesis. This study, however, provided some initial findings and rich qualitative data coming from primarily concurrent verbalizations of the participants. These initial results are worth testing in upcoming studies.

The findings of the study have implications in designing all-inclusive urban environments. Blind individuals' navigation strategies are closely related to sense of enclosure enhanced by solid structures surrounding an individual and the importance of auditory cues in echolocation. Another implication relates to consistency in an urban environment, which supports and sustains familiarity with a particular urban environment. Familiarity is very important in the navigation of all people, but especially for blind individuals. Urban heritage is a key element in our familiarity with our surroundings. The features of an urban environment that constitute the urban heritage create a unique urban identity and strong reference points in the city. The bakery that is located at the same corner for many years can become a strong reference point and the main landmark of the city for all people. It can be a visual landmark for sighted people and an olfactory landmark for blind individuals. The places that are located at the same place and preserved for many years carry on the identity and culture of cities. As long as such places exist, we will need to do less to make way-finding easier.

\section{Disclosure of conflict of interest}

The authors declare that there are no conflicts of interest.

\section{Note}

${ }^{1}$ All concurrent verbalizations have been translated into English by the authors.

\section{References}

American Foundation for the Blind. (2015). American Foundation for the Blind. Retrieved from http://www.afb.org/default.aspx

Ashmead, D. H., \& Wall, R. S. (1999). Auditory perception of walls via spectral variations in the ambient sound field. Journal of Rehabilitation Research and Development, 36, 313-322.

Bloomer, K. C., \& Moore, C. W. (1977). Body, memory and architecture. New Haven, CT: Yale University Press.

Corazzini, L. L., Tinti, C., Schmidt, S., Mirandola, C., \& Cornoldi, C. (2010). Developing spatial knowledge in the absence of vision: Allocentric and egocentric representations generated by blind people when supported by auditory cues. Psychologica Belgica, 50, 327-334. https://doi.org/10.5334 /pb-50-3-4-327

Coughlan, J., \& Manduchi, R. (2009). Functional assessment of a camera phone-based wayfinding system operated by blind and visually impaired users. International Journal on Artificial Intelligence Tools, 18, 379-397. https://doi.org/10.1142 /S0218213009000196

Dodds, A. G., Howarth, C. I., \& Carter, D. C. (1982). The mental maps of the blind: The role of previous visual experience. Journal of Visual Impairment and Blindness, 76, 5-12.

Ferdenzi, C., Coureaud, G., Camos, V., \& Schaal, B. (2010). Attitudes toward everyday odors for children with visual impairments: A pilot study. Journal of Visual Impairment and Blindness, 104, 55-59.

Freksa, C. (1999). Spatial aspects of task-specific wayfinding maps. In J. S. Gero \& B. Tversky (Eds.), Visual and spatial reasoning in design (pp. 15-32). Sydney, Australia: Key Centre of Design Computing and Cognition, University of Sydney.

Gaunet, F. (2006). Verbal guidance rules for a localized wayfinding aid intended for blind-pedestrians in urban areas. Universal Access in the Information Society, 4, 338-353. https://doi.org /10.1007/s10209-003-0086-2

Gaunet, F., \& Briffault, X. (2005). Exploring the functional specifications of a localized wayfinding verbal aid for blind pedestrians: Simple and structured urban areas. Human-Computer Interaction, 20, 267-314. https://doi.org/10.1207 /s15327051hci2003_2

Giudice, N. A., Bakdash, J. Z., \& Legge, G. E. (2007). Wayfinding with words: Spatial learning and navigation using dynamically updated verbal descriptions. Psychological Research, 71, 347-358. https://doi.org/10.1007/s00426-006-0089-8

Herman, J. F., Herman, T. G., \& Chatman, S. P. (1983). Constructing cognitive maps from partial information: A demonstration 
study with congenitally blind subjects. Journal of Visual Impairment and Blindness, 77, 195-198.

Kellogg, W. N. (1962). Sonar system of the blind. Science, 137, 399-404. https://doi.org/10.1126/science.137.3528.399

Koutsoklenis, A., \& Papadopoulos, K. (2011). Olfactory cues used for wayfinding in urban environments by individuals with visual impairments. Journal of Visual Impairment and Blindness, 105, 692-702.

Leonard, J. A., \& Newman, R. (1967). Spatial orientation in the blind. Nature, 215, 1413-1414. https://doi.org/10.1038/2151413a0

Millar, S. (1988). Models of sensory deprivation: The nature/nurture dichotomy and spatial representation in the blind. International Journal of Behavioral Development, 11, 69-87. https://doi.org/10.1177/016502548801100105

Millar, S. (1994). Understanding and representing space: Theory and evidence from studies with blind and sighted children. Oxford, England: Clarendon Press.

Pallasmaa, J. (2005). The eyes of the skin: Architecture and the senses. Chichester, England: Wiley.

Passini, R., \& Proulx, G. (1988). Wayfinding without vision: An experiment with congenitally totally blind people. Environment and Behavior, 20, 227-252. https://doi.org/10.1177 /0013916588202006

Portugali, J. (1996). The construction of cognitive maps. Dordrecht, The Netherlands: Kluwer Academic Publishers.

Rice, C. E. (1967). Human echo perception. Science, 155, 656-664. https://doi.org/10.1126/science.155.3763.656

Saerberg, S. (2010). "Just go straight ahead": How blind and sighted pedestrians negotiate space. Senses and Society, 5, 364-381. https://doi.org/10.2752/174589210X12753842356124

Schenkman, B. N., \& Nilsson, M. E. (2010). Human echolocation: Blind and sighted persons' ability to detect sounds recorded in the presence of a reflecting object. Perception, 39, 483-501. https://doi.org/10.1068/p6473

Steyvers, F. J. J. M., \& Kooijman, A. C. (2009). Using route and survey information to generate cognitive maps: Differences between normally sighted and visually impaired individuals. Applied Cognitive Psychology, 23, 223-235. https://doi.org/10 .1002/acp.1447

Thinus-Blanc, C., \& Gaunet, F. (1997). Representation of space in blind persons: Vision as a spatial sense? Psychological Bulletin, 121, 20-42. https://doi.org/10.1037/0033-2909.121.1.20 